\title{
Availability and Affordability of Children Essential Medicines in Health Facilities of Southern Nations, Nationalities, And People Region, Ethiopia: Key Determinants for Access.
}

Tefera Tadesse

E-Da Hospital

Habtamu Abuye L ( $\nabla$ harohabe@gmail.com )

Wachemo university https://orcid.org/0000-0001-6242-9329

Gizachew Tilahun

Jimma University

\section{Research article}

Keywords: Essential medicine, children, availability, affordability, price, SNNPR, Ethiopia

Posted Date: December 2nd, 2020

DOI: https://doi.org/10.21203/rs.3.rs-115159/v1

License: (c) (i) This work is licensed under a Creative Commons Attribution 4.0 International License. Read Full License

Version of Record: A version of this preprint was published at BMC Public Health on April 13th, 2021. See the published version at https://doi.org/10.1186/s12889-021-10745-5. 


\section{Abstract}

Background: Children in resource-limited countries are more likely to die from treatable conditions than those in higher resource settings due to a lack of the right essential medicine at the right time. Globally millions of children die every year from conditions that could be treatable with existing medicines before they reach their fifth birthday. This study aimed in assessing the availability and affordability of essential medicine for children in selected health facilities of southern nations, nationalities, and peoples' regions (SNNPR), Ethiopia.

Method: A medicine outlets-based cross-sectional study was conducted to assess the availability, affordability, and prices of the 30 selected EMs for children in 30 public and 30 private medicine outlets in SNNPR from March 29 to May 5, 2019, applying WHO and Health Action International (HAl) tools. Availability was expressed as the percentage of sampled medicine outlets per sector that the surveyed medicine was found on the day of data collection. The number of daily wages required for the lowest-paid government unskilled worker (LPGW) to buy one standard treatment of an acute condition or treatment for a chronic condition for a month was used to measure affordability and median price ratio for the price of EDs.

Results: Availability was varied by sectors, type of medicines, and level of health facilities. The average availability of EMs was $57.67 \%$ in the public sector and $53.67 \%$ in private sectors. Ceftriaxone, ORS, zink sulfate, and cotrimoxazole were the most widely available medicine types in both sectors. The median price ratios (MPR) for lowest-priced (LP) medicines were 1.26 and 2.24 times higher than their international reference price (IRP) in the public and private sectors respectively. Eighty-two percent of LP medicines in the public and ninety-one percent of LP medicines in the private sectors used in the treatments of prevalent common conditions in the region were unaffordable as they cost a day's or more wages for the LPGW.

Conclusion: Availability, affordability, and price are determinant pre-requisite for EMs access. According to the current work, although fair availability was achieved, the observed high price affected affordability and hence access to EMs.

\section{Introduction}

The pleasure of the highest achievable standard of health is one of the basic rights of every human being. ${ }^{1}$ Individual and every global society have a task to see the right to health progressively realized. One of the tools that make this right well-functioning is accessing essential medicines (EMs). It is EMs that satisfies the priority health care needs of the communities. ${ }^{2}$ They are chosen with the view of community health relevance, evidence on efficacy, safety, and comparative cost-effectiveness. ${ }^{3}$ EMs are expected to be available within the situation of working health systems at all times in adequate amounts, in the proper dosage forms, with assured quality and sufficient information, and at a price, the individual and the society can afford. ${ }^{2}$

However, access to EMs is challenging; especially for children. Some of the factors which impaired children's access to EMs were lack of suitable dosage forms, the high price of medicines, inefficient government procurement culture, extreme mark-ups in the distribution chain, and exaggerated taxes and duties being applied to these medicines. ${ }^{4-7}$ Even though its necessity was emphasized in Millennium Development Goals/MDG/ four and six, and WHO launched the 'Make Medicines Child Size' campaign to enhance the availability of safe, effective, and quality medicines for children by promoting awareness and action through research, regulatory measures, and changes in policy, effective results for it has not yet been achieved. $6,8,9$

Thus, millions of children die every day before they reach their fifth birthday, of conditions that could be treatable with existing EMs globally. Of newborn deaths, $22 \%$ are due to infections such as pneumonia, diarrhea, and malaria. 
Childhood pneumonia and diarrhea are the most important causes of childhood mortality and account for about $30 \%$ of all child deaths worldwide. ${ }^{10,11}$ The majority of these children would endure if they have given an appropriate available EMs. ${ }^{12}$ For instance, oral antibiotics administered in community settings can reduce all sources of neonatal mortality by $25 \%$ and pneumonia-related mortality by $42 \%$; zinc administration for diarrhea management can reduce all-cause mortality by $46 \%{ }^{13,14}$ The scenario worsens in resource-constrained nations. Children in developing countries are more liable to die from treatable conditions than those in higher resource settings due to a lack of access to the correct medication at the right time. ${ }^{15}$

Access to EMs can be determined by availability, affordability, accessibility, acceptability, and quality of the medicines. As per the studies, assuring availability and affordability of medicines play a vital role in improving children's access to EMs in both private and public sectors. Availability is reported as the percentage of medicine outlets in which medicine was found on the day of data collection and affordability, in other words, is estimated by comparing medicine costs to the daily wage of the lowest-paid unskilled government worker. 6,7

A study conducted in South-west Ethiopia, 55.65\% of EMs were available, and considerable price variation among studied sectors impedes access to EMs. ${ }^{16}$ In Western Ethiopia, the average availability of EMs for children was found to be $43 \%$. Again the price was making EMs unaffordable. ${ }^{17}$ This study, therefore, sought to assess the availability and affordability of CEMs based on WHO/HAI methodology to determine children's access EMs in Southern Ethiopia to have a semi-complete picture of the problem together with already published work. ${ }^{17,18}$

\section{Methods}

\section{Study design, area and period}

A medicine outlets-based cross-sectional descriptive study was conducted in the SNNP region, South Ethiopia.

Quantitative data was collected adapting price and availability format prepared by WHO/HAI 'make medicine child-size project' from March 29 to May 5, 2019. ${ }^{19}$

\section{Drug Outlet selection}

Out of 13 administrative zones found in the region, choosing Hawasa, the capital city of the SNNP region as a center for the study, six administrative zones that can be reached within one day were randomly selected. ${ }^{18,19}$ For each district, the higher health facility (HF) in the three-tier system of the country was purposely, one primary hospital and three health centers (HCs) within three hours' travel of the higher HF were randomly selected from the lists of HFs obtained from the regional health bureau of SNNPR for the public sector since primary hospital to HC ratio was 1:12 (SNNP Regional Health Bureau). ${ }^{18-20}$ Similarly, lists of licensed medicine outlets for each district were obtained and closest to each public HFs one pharmacy purposely and four drug-stores were randomly selected for private sectors as a pharmacy to drug-store ratio was 1:15 (SNNP Regional Health Bureau). If there were no private medicine outlets found within a 10km radius of public HF, another was considered in the near urban setting. ${ }^{18}$ Therefore, 60 medicine outlets, 30 from private, and 30 from public sectors were considered in the current study. The chosen medicine outlets were from the different levels of HFs that are expected to stock all of the medicines included in the study.

\section{Selection of medicines}


Twenty-three EMs were taken based on proposed formulations and strength for key tracer children medicines WHO EMLc core list as specified by the 'Better Medicines for Children Project'. ${ }^{19}$ Seven medicines were added in the study list as per the prevalence and burden of diseases associated with childhood illness in the region (SNNP Regional Health bureau). For each surveyed medicine, we collected data on the lowest-priced, highest priced (instead of innovator/brand medicines), and its availability. ${ }^{19}$ But for programed medicines, which are free of charge for the public in the public sector, we checked only their availability.

\section{Data collection and analysis}

Six data collectors were trained as per WHO/HAI methodology to do the collection task. The pre-test was undertaken in Werabe town where the trainees were trained. Being supervised and controlled for quality of data daily by Principal Investigators, 60 medicine outlets were visited to collect data on the availability and patient prices of medicines. The availability of medicine was addressed by interviewing the staff working at the facility and physically checking the study medicines for their presence as stated in the dispensing area. ${ }^{19}$ Patient prices were taken by interviewing the staff working at the facility, reviewing the most recent price data that were recorded on the posted selling price, or referring model 22. For data collection, WHO/HAl standard data collection format was employed (Additional file 1). For tracking the quality, processing in advance, and statistical analysis, collected data were entered into customized MS Excel from the workbook provided as part of the WHO/HAI methodology. All studied medicine outlets fulfil the WHO/HAI recommendation criteria to collect data on the selected 30 medicines (Table 1). ${ }^{18}$ 
Table 1

List of medicine surveyed in Southern Ethiopia

\section{S.No. Name of Medicine}

1. Amoxicillin

2. Amoxicillin

3. Amoxicillin+Clavulanic acid

4. Amoxicillin+Clavulanic acid

5. Ampicillin

6. Artemether + Lumefantrine

7. Artesunate

8. Beclomethasone inhaler

9. Benzylpenicillin

10. Carbamazepine

11. Ceftriaxone injection

12. Chloramphenicol injection

13. Cloxacillin

14. Cotrimoxazole (Sulphamethoxazole + Trimethoprim)

15. Diazepam I injection

16. Ferrous salt

17. Gentamycin

18. Ibuprofen

19. Isoniazide

20. Morphine

21. Oral Rehydration Solution

22. Paracetamol

23. Paracetamol

24. Penicillin G, Benzathine penicillin

25. Phenobarbitone

26. Phenytoin

27. Procaine penicillin injection

28. Salbutamol Puff

29. Vitamin A
Strength

$125 \mathrm{mg} / \mathrm{ml}$

$250 \mathrm{mg}$

$125+31.25 \mathrm{mg} / 5 \mathrm{ml}$

$125 \mathrm{mg}+31.25 \mathrm{mg}$

$500 \mathrm{mg}$

$20 \mathrm{mg}+120 \mathrm{mg}$

$60 \mathrm{mg}$

$100 \mathrm{mcg} /$ dose

$1 \mathrm{MIU}$

$100 \mathrm{mg} / 5 \mathrm{ml}$

$1 \mathrm{~g}$

$1 \mathrm{~g}$

$125 \mathrm{mg} / 5 \mathrm{ml}$

$200 \mathrm{mg}+40$

$\mathrm{mg} / 5 \mathrm{ml}$

$5 \mathrm{mg} / \mathrm{ml}$

$30 \mathrm{mg} \mathrm{Fe} / 5 \mathrm{ml}$

$40 \mathrm{mg} / \mathrm{ml}$

$100 \mathrm{mg} / 5 \mathrm{ml}$

$100 \mathrm{mg}$

$10 \mathrm{mg} / 5 \mathrm{ml}$

1 litter

$120 \mathrm{mg} / 5 \mathrm{ml}$

$125 \mathrm{mg}$

1.2MIU

$30 \mathrm{mg}$

$50 \mathrm{mg}$

$1 \mathrm{MIU}$

$100 \mathrm{mcg} /$ dose

$100,000 I U$
Dosage Form

Suspension Infectious disease

Dispersible Infectious disease tab

Suspension Infectious disease

Dispersible Infectious disease tab

Injection Infectious disease

Tablet

Injection

Inhaler

Powder

Suspension

Powder

Powder

Suspension

Suspension

Solution

Suspension

Injection

Syrup

Tablet

Oral Solution

Powde

Syrup

Suppository

Injection

Syrup

Suspension

Powder

Inhaler

Capsule
Malaria

Malaria

Asthma

Infectious disease

Seizure disorder

Severe infection

Infectious disease

Infectious disease

Pneumonia

Seizure disorder

Anemia

Infectious disease

Pain/inflammation

TB

Dehydration

Pain

Pain

Infectious disease

Seizure disorder

Seizure disorder

Infectious disease

Asthma

Xerophthalmia 


\section{Measuring availability and affordability of medicines}

The availability of individual medicine was measured by the physical presence of them in the medicine outlets during data collections. ${ }^{19}$ It was expressed as the percentage of sampled medicine outlets per sector that the surveyed medicine was found on the day of data collection. ${ }^{21}$ This work applied percentage ranges: < 30\% very low, 30-49\% low, $50-80 \%$ fairly high, and $>80 \%$ high availability to express its findings. ${ }^{22}$

IRP was used for comparing the prices of 17 lowest-priced medicines. ${ }^{23}$ Patient prices were reported as median price ratios (MPRs), which expressed as median local unit prices across health facilities divided by their median IRPs. ${ }^{24}$

\section{$M P R=\frac{\text { Median Local Unit Price }}{\text { International Reference Unit Price }}$}

The local unit price was obtained by dividing the retail price per pack by the pack size. The supplier medicine prices obtained from the MSH drug price guide 2015 were taken as the IRPs for core medicines (Additional file 1). ${ }^{23}$ MPR was calculated by converting the median local price to United States Dollar (USD) using the exchange rate of commercial banks of Ethiopia at first data of data collection, March 29, 2019. ${ }^{25}$

Affordability was estimated by comparing the total price required to cover the complete course of standard treatment for prevalent diseases in the region (SNNP Regional Health bureau) with the number of daily wages of the LPGW, which was 28.57 ETB per day (0.99 USD) during data collection (Ethiopian ministry of finance and economics salary scale for the public sector) ${ }^{26}$ Medicines used to manage asthma (chronic condition) and six acute conditions were chosen based on WHO/HAI Standards. ${ }^{18,19}$ For each condition, the lowest-priced medicine costs were computed and compared. The total costs of medicine for the complete duration of therapy of acute conditions and a one-month course of chronic conditions were determined and converted to the daily wage. Then, description has given as medicines that costed less than a day's wage to buy one standard treatment of an acute condition or treatment for a chronic condition for a month are affordable and unaffordable if they cost more. ${ }^{24}$

\section{Results}

\section{Availability of EMs}

Availability was varied by type of medicine, sectors, and level of health facilities. Ceftriaxone, ORS, zink sulfate, and cotrimoxazole were available in more than $90 \%$ of medicine outlets. On the other hand, none of the sectors stocked beclomethasone inhaler, morphine $10 \mathrm{mg}$ syrup, and carbamazepine $100 \mathrm{mg}$ syrup while isoniazid $100 \mathrm{mg}$ tablet and vitamin A capsules being stocked by public sectors. The availability of nine studied medicines was less than $50 \%$. Public sectors hold lowest-priced medicines, unlike private sectors which had both the lowest and highest priced medicines (see Table 2). 
Average availability of individual children essential medicines in the public and private sectors.

\section{Name of medicine, strength, dosage form}

\section{Percentage of outlets where medicine} found

\begin{tabular}{|c|c|c|c|}
\hline & \multirow{2}{*}{ 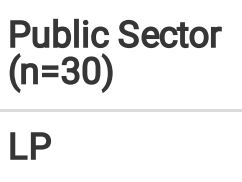 } & \multicolumn{2}{|c|}{$\begin{array}{l}\text { Private Sector } \\
(n=30)\end{array}$} \\
\hline & & LP & HP \\
\hline Amoxicillin 250mg Dispersible tablet & 53.33 & 13.33 & 0 \\
\hline Amoxicillin $125 \mathrm{mg} / 5 \mathrm{ml}$ Suspension & 86.67 & 93.3 & 6.67 \\
\hline Amoxicillin + Clavulinc acid $125 \mathrm{mg}+31.25 \mathrm{mg}$ Dispersible tablet & 6.67 & 6.67 & 0 \\
\hline Amoxicillin + Clavulanic acid $125 \mathrm{mg}+31.25 \mathrm{mg} / 5 \mathrm{ml}$ Suspension & 66.67 & 86.67 & 20 \\
\hline Ampicillin 500mg Powder for Injection & 73.33 & 70 & 0 \\
\hline Artemether + Lumefantrine $20 \mathrm{mg}+120$ mg Dispersible Tab & 76.67 & 83.33 & 0 \\
\hline Artesunate $60 \mathrm{mg}$ powder for Injection & 30 & 10 & 0 \\
\hline Benzylpenicillin 1 MIU Powder for Injection & 56.67 & 26.67 & 0 \\
\hline Beclomethasone $100 \mathrm{mcg} /$ dose inhaler & 0 & 0 & 0 \\
\hline Carbamazepine 100mg/5ml Suspension & 0 & 0 & 0 \\
\hline Ceftriaxone 1g Powder for Injection & 90 & 100 & 23.33 \\
\hline Chloramphenicol 1g Powder for Injection & 13.33 & 6.67 & 0 \\
\hline Cloxacillin $125 \mathrm{mg} / 5 \mathrm{ml}$ Suspension & 66.67 & 60 & 0 \\
\hline $\begin{array}{l}\text { Cotrimoxazole (Sulphamethoxazole + Trimethoprim) 100mg+20 mg } \\
\text { Suspension }\end{array}$ & 86.67 & 100 & 3.33 \\
\hline Diazepam 5mg/ml Injection & 76.67 & 76.67 & 0 \\
\hline Ferrous salt 30mg/5ml Suspension & 66.67 & 83.33 & 6.67 \\
\hline Gentamycin $40 \mathrm{mg} / \mathrm{ml}$ Injection & 86.67 & 73.33 & 0 \\
\hline Ibuprofen 100mg/5ml Syrup & 73.33 & 86.67 & 0 \\
\hline Isonaized 100mg Tablet & 76.67 & 0 & 0 \\
\hline Morphine $10 \mathrm{mg} / 5 \mathrm{ml}$ Oral Solution & 0 & 0 & 0 \\
\hline Oral Rehydration Solution Powder to make 1 liter & 90 & 100 & 3.33 \\
\hline Paracetamol $120 \mathrm{mg} / 5 \mathrm{ml}$ Syrup & 73.33 & 86.67 & 6.67 \\
\hline Paracetamol 125mg Suppository & 70 & 93.33 & 23.33 \\
\hline Penicillin G, Benzanthine n 1.2MIU for Injection & 76.67 & 73.33 & 0 \\
\hline Phenobarbitone 30mg Tablet & 60 & 36.67 & 0 \\
\hline Phenytoin 50mg Tablet & 46.67 & 40 & 0 \\
\hline Procaine penicillin 1 MIU Powder for Injection & 26.67 & 13.33 & 0 \\
\hline Salbutamol puff $100 \mathrm{mcg} /$ dose Inhaler & 66.67 & 96.67 & 3.33 \\
\hline
\end{tabular}


Vitamin A 100,000IU Capsule

Zinc sulfate $20 \mathrm{mg}$ Tablet
43.33

90
0

93.33
0

0

MIU-Million international unit, IU-International unit, LP-Lowest-priced, HP-Highest-priced

The average availability for lowest-priced medicines in the public and private sectors were $57.67 \%$ and $53.67 \%$ respectively. The highest-priced medicines' average availability in private sectors was found to be $3.87 \%$. When the level of health facility for medicine availability was considered, private pharmacies lead both sectors having $71.6 \%$ followed by General Hospitals, $68.39 \%$ (Table 3).

Table 3

Availability of children essential medicine per study area, sector, and level of health facility in Southern Ethiopia

\begin{tabular}{|c|c|c|c|c|c|c|}
\hline \multirow{3}{*}{ Study Area } & \multicolumn{6}{|c|}{ Average Availability of Medicines } \\
\hline & \multirow{2}{*}{$\begin{array}{l}\begin{array}{l}\text { Public Sector } \\
(n=30)\end{array} \\
\text { LP }\end{array}$} & \multicolumn{2}{|c|}{$\begin{array}{l}\text { Private Sector } \\
(n=30)\end{array}$} & \multirow[t]{2}{*}{$\begin{array}{l}\text { Level of Health } \\
\text { Facility }\end{array}$} & \multicolumn{2}{|l|}{ Sector } \\
\hline & & LP & HP & & $\begin{array}{l}\text { Public Sector } \\
(n=30)\end{array}$ & 57.67 \\
\hline Gurage Zone & 60.00 & 64.44 & 0.74 & & $\begin{array}{l}\text { 1. General } \\
\text { Hospital }\end{array}$ & 68.39 \\
\hline Hadiya Zone & 58.62 & 62.22 & 0.74 & & $\begin{array}{l}\text { 2. Primary } \\
\text { Hospital }\end{array}$ & 58.62 \\
\hline Halaba Zone & 61.38 & 65.19 & 6.67 & & $\begin{array}{l}\text { 3. Health } \\
\text { Center }\end{array}$ & 57.28 \\
\hline Hawasa City & 63.45 & 66.67 & 2.22 & & $\begin{array}{l}\text { Private Sector } \\
(n=30)\end{array}$ & 53.67 \\
\hline $\begin{array}{l}\text { Kembata-Tembaro } \\
\text { Zone }\end{array}$ & 59.31 & 60.74 & 4.44 & & 4. Pharmacy & 71.60 \\
\hline Wolaita Zone & 62.07 & 64.44 & 4.44 & & 5. Drug Store & 62.04 \\
\hline
\end{tabular}

LP-Lowest-priced, HP-Highest-priced

\section{Costs of EMs}

MPR of 17 lowest priced medicines were calculated to estimate price variation of individual medicine across sectors. Accordingly, the MPR $\left(25^{\text {th }}-75^{\text {th }}\right.$ percentile) in public and private sectors was 1.26 and 2.24 respectively. Out of 17 lowest-priced medicines, only ORS and paracetamol $125 \mathrm{mg}$ suppository had an LP MPR $<1$ in the public sectors implying that they were cheaper in the study region compared to the IRPs. Phenobarbitone $30 \mathrm{mg}$ tablet in the public sectors was the most expensive medicine which was sold at 3.23 times its IRP. All medicines encountered in private sectors had an LP MPR >1 implying that they were expensive in the study region compared to the IRPs. The most expensive medicine in the private sector, paracetamol $125 \mathrm{mg}$ suppository (MPR=5.21) found to be the cheapest in the public sector (Table 4). 
Table 4

\begin{tabular}{|c|c|c|}
\hline $\begin{array}{l}\text { List of medicine available in } \\
\text { At least four Medicine outlets }\end{array}$ & Public LP MPR & Private LP MPR \\
\hline Amoxicillin $125 \mathrm{mg} / 5 \mathrm{ml}$ suspension & $1.78(1.6-2.28)$ & $2.27(2.23-2.51)$ \\
\hline Amoxicillin + Clavulinc acid 156.25 suspension & $1.10(0.83-2.17)$ & $2.52(2.33-2.59)$ \\
\hline Ampicillin 500mg powder for injection & $1.85(1.16-2.09)$ & $3.01(2.5-3.31)$ \\
\hline Ceftriaxone $1 \mathrm{gm}$ powder for injection & $1.69(1.32-1.86)$ & $2.29(2.17-2.42)$ \\
\hline Cloxacillin $125 \mathrm{mg} / 5 \mathrm{ml}$ suspension & $1.04(0.58-1.06)$ & $1.17(0.92-1.29)$ \\
\hline Cotrimoxazole $240 \mathrm{mg} / 5 \mathrm{ml}$ suspension. & $1.26(1.17-1.68)$ & $2.09(1.72-1.26)$ \\
\hline Diazepam $5 \mathrm{mg} / \mathrm{ml}$ injection & $1.37(1.03-1.54)$ & $1.65(1.36-1.97)$ \\
\hline Ferrous sulfate $30 \mathrm{mg} / 5 \mathrm{ml}$ & $1.02(0.28-1.04)$ & $1.09(0.29-1.3)$ \\
\hline Gentamycin $40 \mathrm{mg} / \mathrm{ml}$ injection. & $1.24(0.74-1.46)$ & $1.75(1.13-2.04)$ \\
\hline Ibuprofen $100 \mathrm{mg} / 5 \mathrm{ml}$ syrup & $2.36(1.99-2.68)$ & $3.15(2.68-3.43)$ \\
\hline ORS to make $1 \mathrm{~L}$ & $0.95(0.72-2.06)$ & $3.67(2.45-4.12)$ \\
\hline Paracetamol $125 \mathrm{mg}$ suppository & $0.65(0.64-0.74)$ & $5.21(3.82-6.79)$ \\
\hline Paracetamol $120 \mathrm{mg} / 5 \mathrm{ml}$ syrup & $1.51(0.94-1.95)$ & $2.24(1.80-3.23)$ \\
\hline Penicillin G,Benzthine 1.2MIU & $1.99(1.49-2.5)$ & $2.78(2.5-3.23)$ \\
\hline Phenobarbitone 30mg tablet & $3.23(2.71-3.55)$ & $3.78(2.89-4.85)$ \\
\hline Phenytoin 50mg tablet & $1.10(0.5-1.2)$ & $1.19(0.75-2.28)$ \\
\hline Salbutamol puff $100 \mathrm{mcg} /$ dose inhaler & $1.69(1.22-1.83)$ & $1.92(1.83-2.47)$ \\
\hline
\end{tabular}

As seen in Figure 1, the MPR for lowest-priced medicines in the public sector was twice lesser than private MPR (1.26:2.24-Public sectors to Private sectors). The average LP MPR for the 17 medicines in the public and private sectors was 1.57 and 2.54 respectively. Patients in the study area were paying higher prices than the median IRPs for 15/17 medicines in the public and all medicines in private sectors. Generally, medicines in this survey sold at price higher than their IRPs.

\section{Treatment affordability for prevalent disease with EMs}

Assuming all wages go for drug purchasing, Table 5 revealed $81.82 \%(9 / 11)$ and $91.91 \%(10 / 11)$ of standard treatments for prevalent diseases in the public and private sectors with the LP medicines was unaffordable respectively. ${ }^{27}$ It would take a day and above to purchase all the studied medicines except ORS and paracetamol $125 \mathrm{mg}$ suppository, which would require 0.2 and 0.5 days' wages to pay for the recommended dosage respectively. In both sectors, treating acute 
otitis media with Augmentin $156 \mathrm{mg} / 5 \mathrm{ml}$ for the duration of 10 days was found to be very costly. It required 3.4 and 7.8 day's wage for LPGW to afford it in public and private sectors respectively. 
Affordability: cost required to cover full course standard treatment against the number of daily wages.

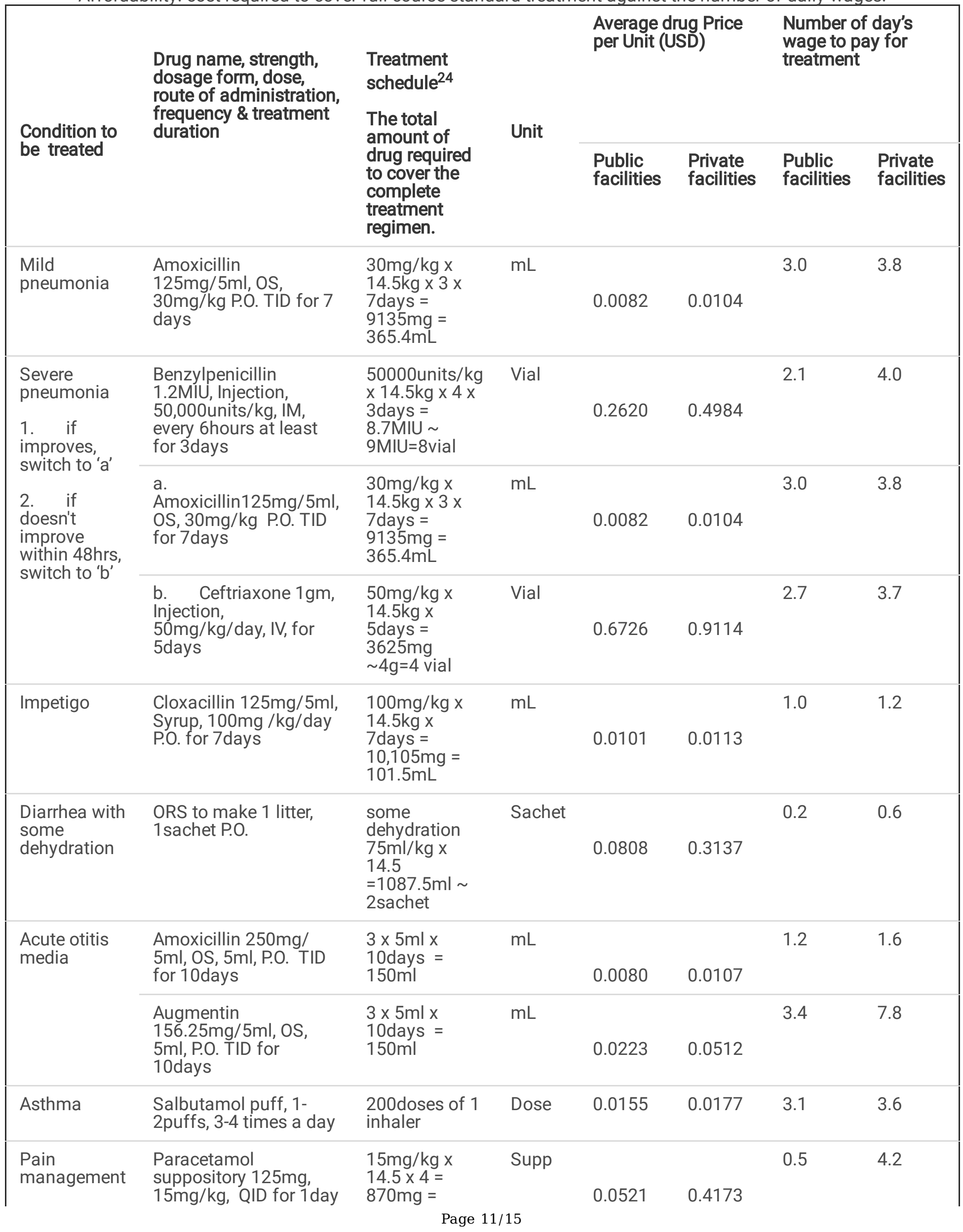




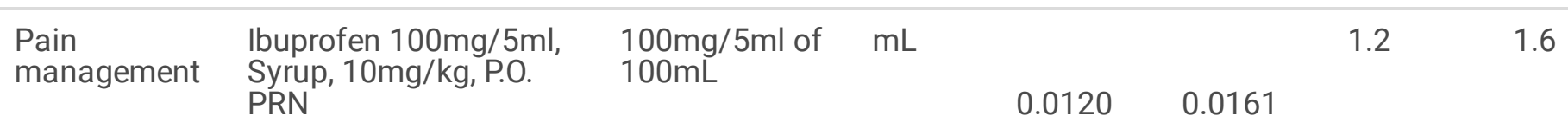

*Average weight of five year age children in Ethiopia $=14.5 \mathrm{~kg}$, OS - Oral Suspension, P.O-Per oral, TID - Three times a day, QID - Four times a day, PRN-When necessary, IM-Intramuscular, IV-Intravenous, Supp-Suppository, USDUnited States of American Dollar.

\section{Discussion}

The result of this study showed the average availability of lowest-priced medicines for children was fairly high in both sectors. $^{22}$ It was $57.67 \%$ and $53.67 \%$ in public and private sectors respectively. However, none of the selected districts' HFs stocked beclomethasone inhaler, morphine $10 \mathrm{mg} / 5 \mathrm{ml}$ oral solution, and carbamazepine $100 \mathrm{mg} / 5 \mathrm{ml}$ suspensions. Regarding the higher availability of medicines in the public sector compared to the private sector, these findings are consistent with the results of a study done by Edao Sado and Alemu Sufa, in the Western part of Ethiopia, for a similar target. ${ }^{17}$ Studies like the compiled reports of WHO and Anson A et al results disagree with the current work by finding low average availability of medicines in the public than private sectors. ${ }^{7,24}$

The average availability of medicines used to treat chronic conditions such as seizure disorders and asthma in children was low $(\approx 42 \%){ }^{22}$ Medicines offered free of charge from the public sectors like artesunate $60 \mathrm{mg}$ and vitamin A were found below $50 \%$. Infectious diseases are known causes of childhood morbidity and mortality. ${ }^{10,11,15}$ The availability of medicine used to tackle these conditions has to be maintained at the optimum level $(\geq 50 \%)$. However, the average availability of chloramphenicol $1 \mathrm{~g}$ was below the 'very low' level. ${ }^{22}$

The current study also showed that the overall retail prices of the lowest-priced mmedicines were higher than their IRPs. They were sold at 1.26 times their IRPs in the public sectors and 2.24 times their IRPs in the private sectors. Concerning substantially higher prices in private sectors compared to public sectors, this finding is similar to the studies done by Edao Sado and Alemu Sufa, and Sun X et al. ${ }^{17,28}$ A noticeable price variability between both sectors was common for captured medicine in this study. It is consistent with a study undertaken on the availability, prices, and affordability of essential medicines in Ethiopia, Haiti, and china $17,22,28$

Managing commonly prevalent conditions-acute and chronic- with standard treatment protocol using the lowestpriced medicines in the region was unaffordable (81.82\% in public and $91.91 \%$ in private) as they cost a day's or above wage for the LPGW. This finding agrees with the findings of Edao Sado and Alemu Sufa, and Sun X et al. ${ }^{17,28}$ The assumption of the LPGW method to assess the affordability of EMs is that all wages go for medicine purchasing. For households that have an average of 4.6 children, spending a day's wage for purchasing medicine only is not evident. ${ }^{29}$ Low-income earners are likely to spend $93 \%$ and $60 \%$ of their income on food, housing, transport, utilities, and sport or leisure activities as per Mokaya $\mathrm{J}$ et al. and Xu K et al. findings respectively. ${ }^{30,31}$ Accordingly, only $7 \%$ and $40 \%$ of day's wage is left for healthcare costs. Therefore, to afford the cheapest lowest-priced medicine ORS in the public sector, the LPGW needs 0.4 to 2.3 day's wage. The expensive standard treatment for acute otitis media with Augmentin $156.25 \mathrm{mg} / 5 \mathrm{ml}$ in private sectors required the LPGW's 19.4 to 110.8 days' wage. Thus, almost all the 11 standard treatment options identified in this work were unaffordable. This may drive parents to forgo treatment or to suspend their basic needs. 


\section{Limitation Of The Study}

This study did not assess factors affecting or related to availability, price, and affordability

\section{Conclusion}

The average availability EMs for children in this work was fairly good. Public sectors have relatively higher availability than private sectors provided that government-subsidized, free of charge offered and public sectors only allowed to stock medicines were included in the study. However, the average LP MPR for public and private sectors being 1.57 and 2.54 times their IRPs compromises children's access to EMs respectively. Furthermore, being unaffordability of LP medicines for $81.82 \%$ and $90.91 \%$ of full-course standard treatments of prevalent conditions in the public and private sectors as they cost a day's or above wages for the LPGW respectively, lowering childhood morbidity and mortality questionable.

\section{Abbreviations}

CEMs-Children essential medicines; EMLc-Essential medicine lists for children; EMs-Essential medicines; ETBEthiopian birr; HAl-Health action international; HC-Health center; HFs-Health facilities; HP-Highest-priced; IRPsInternational reference prices; LPGW-Lowest-paid government unskilled worker; LP-Lowest-priced; MPR-Median price ratio; MS-Microsoft; SNNP-Southern nations nationalities and peoples; WHO-World health organization.

\section{Declarations}

\section{Ethical consideration}

Ethical clearance was obtained from Jimma University Institute of Health Sciences Ethical Review Board after the pharmacy department reviewed and approved the study protocol as it was compiled with the Declaration of Helsinki. A letter of cooperation was written to the regional health bureau and then the regional health bureau to the survey areas health departments to facilitate cooperation for public sectors. Private medicine outlet owners provided informed verbal consent and the confidentiality of collected data was maintained.

\section{Consent for Publication}

Not applicable.

\section{Availability of data and material}

The datasets used and/or analyzed during the current study available from the first author on reasonable request.

\section{Competing interests}

The authors declare that they have no competing interests.

\section{Funding}

The author(s) received no financial support for the research and/or authorship of this article. 


\section{References}

1. World Health Organization. Constitution of the World Health Organization. (WHO, 2006).

2. World Health Organization. Equitable access to essential medicines: a framework for collective action. (WHO, 2004).

3. World Health Organization. The Selection of Essential Medicines. (WHO Policy Perspectives on Medicines, 2002).

4. Schirm, E., Tobi, H., Vries, T. W. De, Choonara, I. \& Berg, L. T. W. D. J. Den. Lack of appropriate formulations of medicines for children in the community. Acta Paediatr 92, 1488-1489 (2003).

5. World Health Organization. WHO Medicines Strategy: Countries at the core. (WHO, 2007).

6. World Health Organization. Access to affordable essential medicines. (WHO, 2003).

7. World Health Organization. Access to essential medicines. (WHO, 2010).

8. United Nations. The Millennium Development Goals Report 2010. (UN, 2010).

9. G, W. WHO launches campaign to make drugs safer for children. BMJ 335, 1227-1233 (2007).

10. Walker, C. L. F. et al. Global burden of childhood pneumonia and diarrhoea. Lancet 381, 1405-1416 (2013).

11. Liu, L. et al. Global , regional , and national causes of under-5 mortality in $2000-15$ : an updated systematic analysis with implications for the Sustainable Development Goals. Lancet 388, 3027-3035 (2016).

12. World Health Organization. Better medicines for children. (WHO, 2007).

13. Zaidi, A. K. M. et al. Effect of case management on neonatal mortality due to sepsis and pneumonia. BMC Public Health 11, S13 (2011).

14. Bhutta, Z. A. et al. Interventions to address deaths from childhood pneumonia and diarrhoea equitably: what works and at what cost? Lancet 381, 1414-1429 (2013).

15. World Health Organization/The United Nations Children's Fund (UNICEF). Ending Preventable Child Deaths from Pneumonia and Diarrhoea by 2025: The integrated Global Action Plan for Pneumonia and Diarrhoea (GAPPD). (WHO, 2013).

16. Abiye, Z., Tesfaye, A. \& Hawaze, S. Barriers to access: availability and affordability of essential drugs in a retail outlet of a public health center in south western Ethiopia. J. Appl. Pharm. Sci. Vol. 3, 101-105 (2013).

17. Sado, E. \& Sufa, A. Availability and affordability of essential medicines for children in the Western part of Ethiopia: implication for access. BMC Pediatr. 16, 1-8 (2016).

18. World Health Organization; Health Action International. Measuring Medicine prices, availability, affordability and price components. (WHO, 2008).

19. Better Medicines for Children Project: Overview of Methods for Medicines Availability and Pricing Surveys. (2009).

20. The Federal Democratic Republic of Ethiopia Ministry of Health. Health Sector Transformation Plan-HSTP 2015/162019/20. (EMoH, 2015).

21. Mhlanga, B. S. \& Suleman, F. Price, availability and affordability of medicines. Afr. J. Prim. Heal. Care Fam. Med. 6, 1-6 (2014).

22. Chahal, H. S., Fort, N. S. \& Bero, L. Availability , prices and affordability of essential medicines in Haiti. J. Glob. Health 3, (2013).

23. Management Sciences for Health/World Health Organization. International Medical Products Price Guide. (MSH, 2016).

24. Anson, A., Ramay, B., Esparza, A. R. De \& Bero, L. Availability , prices and affordability of the World Health Organization 's essential medicines for children in Guatemala. Global. Health 8, 1-10 (2012).

25. Commercial Bank of Ethiopia. http://www.combanketh.et/More/ CurrencyRate.aspx. Accessed 29 Mar 2019. 
26. Cameron, A., Ewen, M., Ball, D. \& Laing, R. Medicine prices , availability , and aff ordability in 36 developing and middle-income countries: a secondary analysis. Lancet 373, 240-249 (2009).

27. Federal Democratic Republic of Ethiopia. Ministry of Health. Hospital Care Pocket Book of Guidelines for the Management of Common IIInesses in Hospitals. (FMHACA, 2010).

28. Sun, X. et al. Availability , prices and affordability of essential medicines for children: a cross- sectional survey in Jiangsu Province, China. BMJ Open 8, 1-12 (2018).

29. Central Statistical Agency and ICF. 2016 Ethiopia Demographic and Health Survey Key Findings. (CSA and ICF, 2017).

30. Mokaya, J., Dotchin, C. L., Gray, W. K., Hooker, J. \& Walker, R. W. The Accessibility of Parkinson 's Disease Medication in Kenya: Results of a National Survey. Mov. Disord. Clin. Pr. 3, 376-381 (2016).

31. Xu, K. et al. Household catastrophic health expenditure: a multicountry analysis. Lancet 362, 111-117 (2003).

\section{Figures}

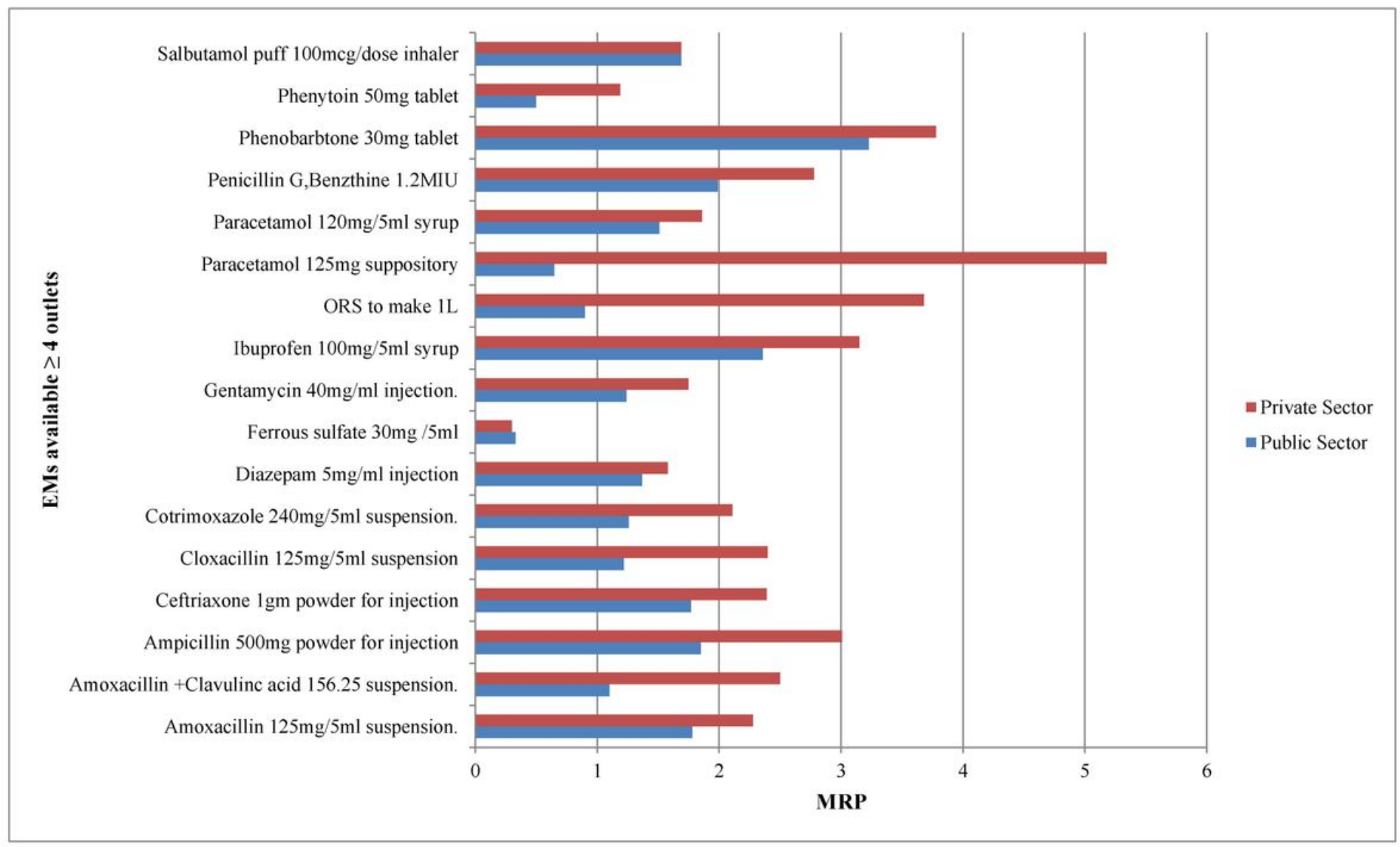

Figure 1

Comparison of MPR of lowest price medicines found in $\geq 4$ drug outlets in public and private sectors.

\section{Supplementary Files}

This is a list of supplementary files associated with this preprint. Click to download.

- AdditionalInformationTef.docx 